\author{
Departement für Nutztiere der Vetsuisse-Fakultät \\ Universität Zürich \\ Klinik für Fortpflanzungsmedizin \\ (Direktor: Prof. Dr. W. Kähn) und \\ Nationalgestüt Avenches \\ (Direktor: Dr. P.A. Poncet)
}

Arbeit unter der Leitung von Dr. F. Janett

\title{
Influence of immunization against GnRH on reproductive cyclicity and estrous behavior in the mare
}

\author{
INAUGURAL-DISSERTATION \\ zur Erlangung der Doktorwürde \\ der Vetsuisse-Fakultät \\ Universität Zürich \\ vorgelegt von \\ Isabel Imboden \\ Tierärztin \\ von Unterseen/BE und St. Gallen \\ Genehmigt auf Antrag von \\ Prof. Dr. R. Thun, Referent \\ Prof. Dr. J. Auer, Korreferent
}

Zürich 2006

Stiftung Zentralstelle Studentendruckerei 


\title{
Influence of immunization against GnRH on reproductive cyclicity and estrous behavior in the mare
}

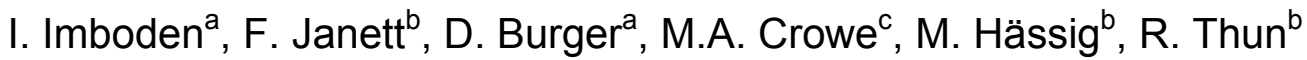 \\ ${ }^{a}$ National Stud, Avenches, Switzerland \\ ${ }^{b}$ Clinic of Reproduction, University of Zürich, Switzerland

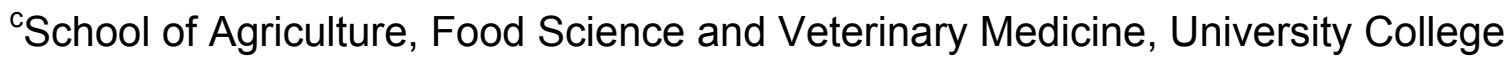 \\ Dublin, Ireland
}

\begin{abstract}
The aim of this study was to evaluate the effect of active immunization against $\mathrm{GnRH}$ on ovarian activity, plasma progesterone and estradiol concentrations and on estrous behavior in adult mares. Eighteen cyclic mares were randomly divided into a treatment and control group. Nine mares were immunized twice with $2 \mathrm{~mL}(400 \mu \mathrm{g} \mathrm{GnRH}$-protein conjugate) of a GnRH-vaccine (Improvac ${ }^{\circledR}, \mathrm{CSL}$ Limited, Australia) administered intramuscularly, 4 weeks apart. Control mares received the same amount of saline solution. Ovaries and uterus of all mares were examined weekly by ultrasonography from 3 weeks before to 60 weeks after the first immunization. Thereafter, vaccinated mares were evaluated monthly until 100 weeks after the first vaccination. In addition, mares were teased with a stallion for assessment of estrous behavior and blood was collected for progesterone, estradiol-17 $\beta$ and $\mathrm{GnRH}$ antibody titer determination. Results demonstrate that vaccination against GnRH significantly $(P<0.05)$ influenced all parameters, except estradiol-17 $\beta$ concentration. All vaccinated mares ceased reproductive cyclicity (plasma progesterone $<1 \mathrm{ng} / \mathrm{mL}$, follicles $<3 \mathrm{~cm}$ ) within 8 weeks after the first injection and ovarian activity remained suppressed for a minimum of 23 weeks. Five mares resumed cyclicity (follicles $>3 \mathrm{~cm}$, progesterone $>1 \mathrm{ng} / \mathrm{mL}$ ) while 3 mares showed only follicular activity (follicles $>3 \mathrm{~cm}$ ) and 1 mare remained completely suppressed for the entire duration of the study. In spite of ovarian suppression, 4 mares expressed sporadic and 1 mare continuous estrous behavior. All 9 control mares showed regular development of large follicles and associated periods of estrous behavior during the breeding season. During the winter months, 6 of them became acyclic, whereas the other 3 continued showing reproductive cyclicity and estrous
\end{abstract}


behavior. In conclusion, reproductive cyclicity in adult mares can be successfully suppressed by immunization against $\mathrm{GnRH}$ but the timing of resumption of cyclicity is highly variable and estrous behavior may occur in spite of ovarian suppression. 


\section{Introduction}

The suppression of sexual behavior in mares has long been an issue for both veterinarians and horse owners. Undesirable behavioral traits, especially during estrus, can make a mare difficult to handle and may have detrimental effects on performance. There are numerous methods for managing this problem. One of the most wide spread is the use of progesterone or progestins to artificially simulate diestrus [1]. However, the possibility of a negative effect on the future breeding prospects after repeated use in prepubertal fillies has been reported [2] and the short duration of action of this hormone, necessitating repeated administration, make its use costly and impractical. More drastic means of suppressing estrous behavior are breeding a mare and accepting the ensuing break in the mares' sporting career, or terminating the pregnancy after maternal recognition and maintenance of the primary Corpus luteum (CL) [3], which poses ethical problems. Ovariectomy is a further alternative, though not always effective, as some mares can continue to show estrous signs [4-6], furthermore it carries the disadvantage of surgical risk and permanently eliminating a mare's reproductive potential. Other methods of reversible suppression of sexual activity that warrant being mentioned are the administration of $\mathrm{GnRH}$ antagonists or agonists [7]. The antagonist antarelix has been shown to reliably postpone ovulation after administration and increase the interovulatory interval [8,9]. Treatment with high doses of agonists can effectively desensitize the pituitary to $\mathrm{GnRH}$ in various species [10]. Horses are on the whole less sensitive to down-regulation, however, prolonged or high dose administration can also result in increased inter-ovulatory intervals [11,12] and in some individuals even in a temporary cessation of ovarian activity $[13,14]$. As all these treatments require frequent administration and generally result in only a short-term effect with highly individual responses, their use for behavioral control is limited.

The manipulation of the reproductive activity of both males and females through the use of a $\mathrm{GnRH}$ vaccine has been extensively studied in many species, including humans and with a wide variety of objectives. In farm animals, this method offers an alternative to surgical castration for minimizing sexual and aggressive behavior, suppressing reproductive function and preventing pregnancy [15-18]. In wild animals, vaccination against $\mathrm{GnRH}$ is considered an effective method for population control [19,20]. Its application in human medicine is as a treatment for prostate cancer [21]. In the field of 
equine reproduction the first report of $\mathrm{GnRH}$ vaccination was also as a possible alternative to surgical castration in either cryptorchid [22] or normal males [23,24]. The principal aims were the evaluation of its effectiveness at inhibiting sexual behavior and libido while safeguarding the reproductive potential of an animal. The first studies in mares $[25,26]$ were aimed primarily at investigating the effect of $\mathrm{GnRH}$ vaccination on gonadotropin secretion. Observations of follicular activity and estrous behavior were not a major part of the experimental design and mares were ovariectomized [25] or the study was terminated [26] before the mares returned to normal ovarian cyclicity; neither study concentrated on the possibility of using this method as an alternative to ovariectomy. Two further studies have been reported [27,28]: one documented effective suppression of ovarian function and estrous behavior along with a subsequent reversal of these effects in six 2-year-old fillies [27]; the second study on mature mares showed a greater individual variation and less reliability of the vaccination [28] .

The aim of the present experiment was to investigate the influence of active immunization against $\mathrm{GnRH}$ on reproductive cyclicity, hormone levels and antibody titers in a relatively large group of mature mares. This included evaluation of its influence on the ovaries and uterus, the duration of action, effects on estrous behavior and adverse reactions to the vaccine. 


\section{Materials and methods}

\subsection{Experimental design}

Eighteen barren light-horse mares, aged between 3 and 17 years, (mean age 7.8 years) were used for the experiment. They had variable reproductive histories, but none had been bred within the last 2 years. All mares showed normal reproductive cyclicity with typical signs of behavioral estrus prior to treatment. The mares were randomly allocated to a control and a treatment group of nine mares each (mean age 7.2 and 8.4 years respectively). The treatment consisted of two vaccinations four weeks apart using a commercially available anti-GnRH vaccine (Improvac $^{\circledR}$, CSL Limited, Australia) developed in Australia to control boar taint in pigs. Improvac ${ }^{\circledR}$ contains a synthetic analogue to $\mathrm{GnRH}$ linked to a carrier protein and accompanied by an aqueous adjuvant (200 $\mu \mathrm{g} \mathrm{GnRH-protein} \mathrm{conjugate} \mathrm{per} \mathrm{mL}$ ). The dosage used for both initial and booster vaccination was $400 \mu \mathrm{g} \mathrm{GnRH}$-protein conjugate $(2 \mathrm{~mL})$. Control animals received an equivalent volume of saline solution. All injections were applied intramuscularly into the left side of the neck. The experiment started at the end of March and initial vaccination took place at the end of April. Adverse effects were monitored by twice daily clinical examination with particular regard to body temperature, signs of tissue reaction at the site of injection and stiffness of the neck. Mares were examined for 3 days after vaccination or until all reactions had subsided.

\subsection{Ovarian activity, uterine changes and estrous behavior}

The mares' genital tracts were examined by means of transrectal ultrasonography with a $5 \mathrm{MHz}$ linear array probe (Aloka Echocamera SSD-500, Aloka Holding Europe, Zug, Switzerland). At each scanning session, the ovaries were measured in two perpendicular dimensions. The number and diameters of all follicles larger than $1 \mathrm{~cm}$ in diameter were recorded and assigned to one of 3 categories: small follicles, $<2 \mathrm{~cm}$ in diameter; medium follicles, $2-3 \mathrm{~cm}$ in diameter and large follicles, $>3 \mathrm{~cm}$ in diameter. The diameter of the largest follicle (to the nearest $0.5 \mathrm{~cm}$ ) present on either ovary was recorded separately. The presence of a CL was also noted. The amount of edema in the uterine wall was scored as 1 (homogeneous in appearance, non edematous), 2 
(mildly heterogenous, slightly edematous) or 3 ("wagon wheel" appearance, highly edematous) [29].

Mares without a clearly visible CL were teased with a stallion after each scanning session. Four characteristic estrous signs were noted: tail raising, receptivity to the stallion, clitoral eversion and urination. Excessive kicking, flattening of ears and total lack of interest in the stallion were judged as negative signs. For a mare to be considered as showing typical estrus, at least 3 of 4 positive signs and no negative signs had to be observed. Over the course of 64 weeks ( 3 weeks before to 60 weeks after the primary immunization) mares were examined at weekly intervals (period 1). Mares in the treatment group that had not yet returned to normal reproductive cyclicity after week 60 were examined monthly until they showed a resumption of ovulation (period 2). Examinations were discontinued after a maximum of 100 weeks.

\subsection{Definition of reproductive activity}

Mares were considered to be acyclic when no large follicles were recorded, no CL was visible and progesterone values were lower than $1 \mathrm{ng} / \mathrm{mL}$ for at least 4 consecutive weeks. If the criteria were fulfilled only during short periods of 1 to 3 weeks, these were regarded as periods of temporary follicular quiescence. After an acyclic period, mares were judged as having resumed follicular activity when large follicles ( $>3 \mathrm{~cm}$ diameter) were recorded. When the mares with follicular activity showed a rise in progesterone (plasma progesterone concentration $>1 \mathrm{ng} / \mathrm{ml}$ ) indicating ovulation and formation of a functional CL, they were judged as having resumed ovulatory activity. The period of ovarian suppression was defined as the number of weeks between cessation of all cyclic activity and resumption of follicular activity (no less than 4 weeks).

\subsection{Hormone analysis and GnRH antibody titers}

Blood samples (EDTA) were collected at each examination by jugular venipuncture, immediately centrifuged (4000 $\mathrm{g}, 10 \mathrm{~min})$ and the plasma frozen $\left(-20^{\circ} \mathrm{C}\right)$ until analysis. Progesterone and estradiol-17ß concentrations were measured using electrochemiluminescence immunoassay (Elecsys 2010, Roche Diagnostics, Basel, Switzerland). The detection limit of the assay was $0.03 \mathrm{ng} / \mathrm{mL}$ for progesterone and 3.1 
$\mathrm{pg} / \mathrm{mL}$ for estradiol-17ß. Inter- and intraassay coefficients of variation for progesterone were $2.8 \%$ and $2.2 \%$ respectively and for estradiol- $17 ß 6.5 \%$ and $2.5 \%$ respectively. Antibody titers against $\mathrm{GnRH}$ were determined using a radio ligand binding assay as described previously [30]. Results are presented as percentage of total $1^{125}$-labelled $\mathrm{GnRH}$ bound at a plasma dilution of 1:40.

\subsection{Statistical analysis}

Statistical analysis was performed using the Statview 5.0 software program (SAS Institute, Switzerland). A multivariate analysis of variance (ANOVA) was carried out to assess the effects of treatment and time on ovarian and uterine parameters as well as on plasma progesterone and estradiol concentrations. Differences between the groups in weekly parameter means were compared with the unpaired $t$-test. Values were considered to be statistically significant at $P<0.05$. 


\section{Results}

\subsection{Ovarian and uterine changes}

Means ( \pm S.E.M.) of all parameters measured in the treatment and the control group from week 1 to 60 are presented in Table 1.

\section{Table 1}

Mean ( \pm S.E.M.) of reproductive activity parameters examined weekly during 60 weeks in $\mathrm{GnRH}$ immunized $\left(\right.$ Improvac $\left.^{\circledR}\right)$ and control mares $(n=9$, each) and the statistical significance of the influence of treatment and time of examination

\begin{tabular}{lcccc}
\hline Parameter & $\begin{array}{l}\text { GnRH } \\
\text { immunized }\end{array}$ & Control & $\begin{array}{l}\text { Treatment } \\
(P)\end{array}$ & $\begin{array}{l}\text { Time } \\
(P)\end{array}$ \\
\hline Number of small follicles & $4.9 \pm 0.20$ & $6.7 \pm 0.20$ & $<0.0001$ & $<0.0001$ \\
Number of medium follicles & $0.8 \pm 0.10$ & $3.0 \pm 0.10$ & $<0.0001$ & 0.0004 \\
Number of large follicles & $0.1 \pm 0.02$ & $0.8 \pm 0.05$ & $<0.0001$ & 0.0228 \\
Diameter of largest follicle (cm) & $1.5 \pm 0.04$ & $2.8 \pm 0.05$ & $<0.0001$ & $<0.0001$ \\
Ovarian diameter (cm) & $4.2 \pm 0.03$ & $5.3 \pm 0.03$ & $<0.0001$ & $<0.0001$ \\
Number of CL & $0.2 \pm 0.02$ & $0.7 \pm 0.03$ & $<0.0001$ & $<0.0001$ \\
Uterine edema score ${ }^{\text {a) }}$ & $1.3 \pm 0.03$ & $1.7 \pm 0.03$ & $<0.0001$ & 0.0113 \\
Progesterone $(\mathrm{ng} / \mathrm{mL})$ & $1.2 \pm 0.17$ & $6.8 \pm 0.36$ & $<0.0001$ & $<0.0001$ \\
Estradiol-17 $\beta(\mathrm{pg} / \mathrm{mL})$ & $24.4 \pm 0.44$ & $24.8 \pm 0.35$ & 0.216 & $<0.0001$ \\
\hline a) 1: homogenous, 2: slightly heterogenous, mildly edematous, 3: wagon wheel appearance \\
highly edematous
\end{tabular}

Vaccination against $\mathrm{GnRH}$ significantly $(P<0.05)$ influenced all parameters, except plasma estradiol-17 $\beta$ concentration. Fig. 1 shows the mean number of large follicles (a), mean diameter of the largest follicle (b) and mean ovarian diameter (c) in treated and control mares from 3 weeks before until 60 weeks after first immunization. 


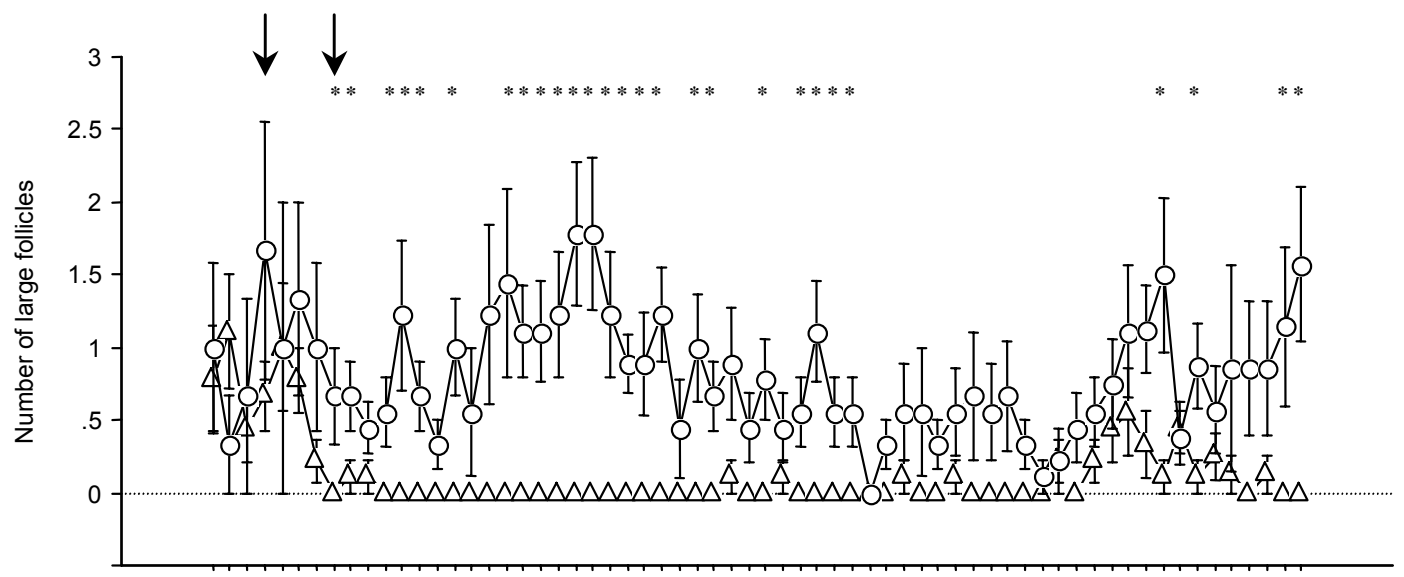

(a)

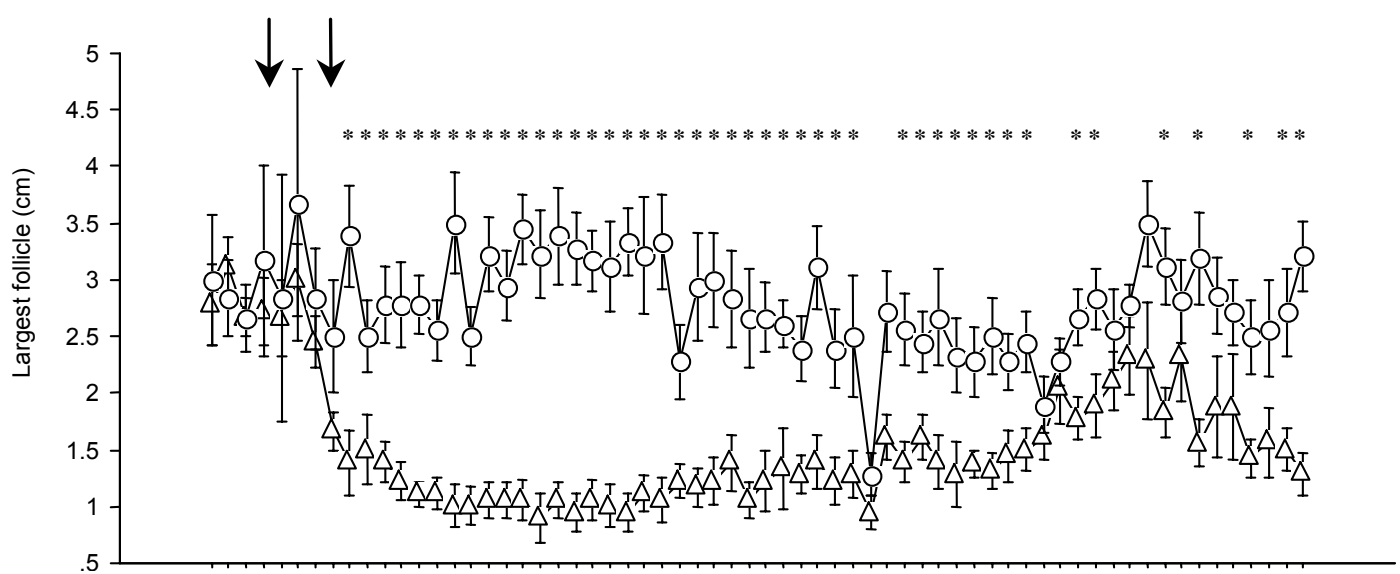

(b)

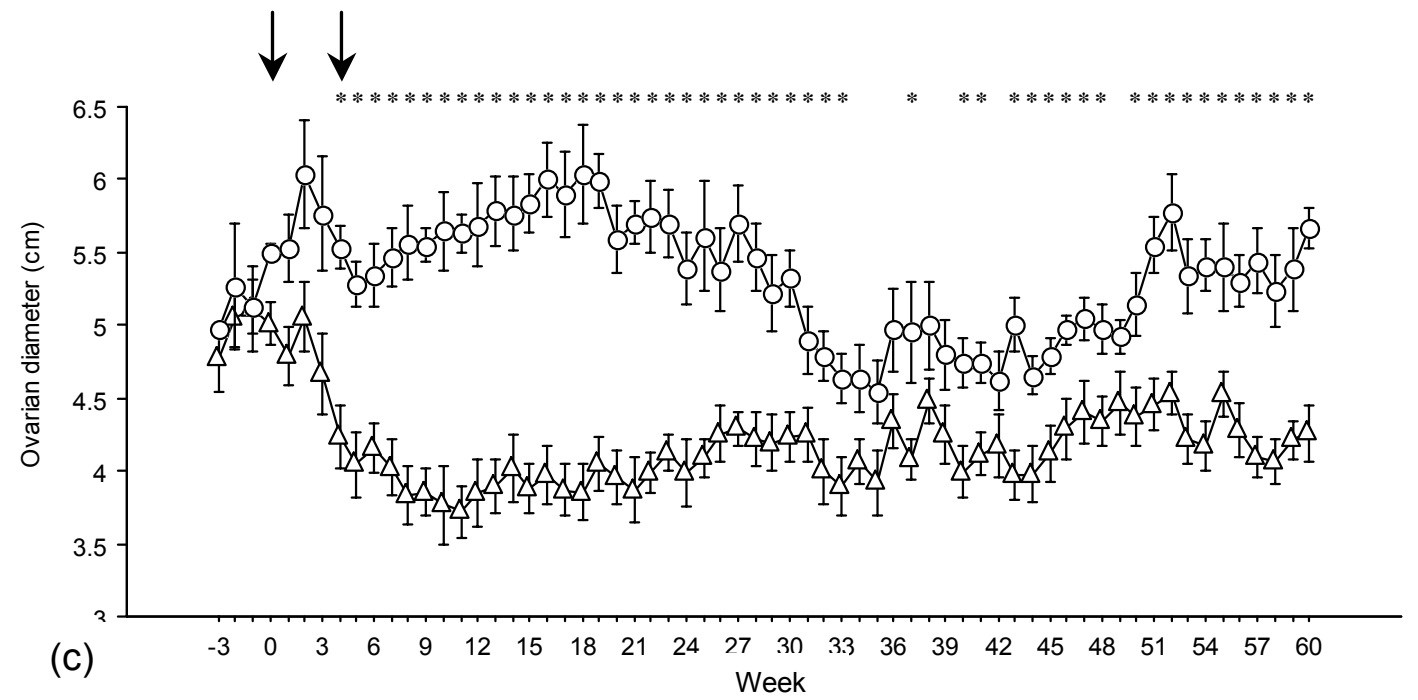

Fig. 1. Mean ( \pm S.E.M.) number of large follicles (a), diameter of the largest follicle (b) and ovarian diameter $(c)$ in vaccinated $(\triangle)$ and control $(\bigcirc)$ mares before and after immunization $(\downarrow)$. Asterisks indicate a significant difference $(P<0.05$, unpaired $t$-test) between groups. 
Before the first vaccination there were no significant differences between the groups. The mean number of large follicles (Fig. 1a) in vaccinated mares decreased rapidly after the first vaccination and large follicles were completely absent from weeks 7 to 26 . The mean number of large follicles remained below 1 until the end of period 1. These changes were also reflected by the mean diameters of the largest follicle (Fig. 1b), which in vaccinated mares dropped below $2 \mathrm{~cm}$ in week 4 and remained between 1 and $2 \mathrm{~cm}$ for 41 consecutive weeks. Mean diameters of the largest follicle in control mares only dropped below $2 \mathrm{~cm}$ in weeks 35 and 45 . The difference between the groups was significant $(P<0.05)$ during weeks 5 to 35 . Mean ovarian diameters were also significantly $(P<0.05)$ lower in vaccinated mares from week 4 to 33 (Fig. 1c).

Fig. 1 shows that mares in the control group continued normal cyclic activity with regular development of large follicles. As the study progressed into the winter months (weeks 32 to 46), most of the control mares gradually entered seasonal anestrus, showing reduced follicular activity and ovarian diameter. The weekly differences between the 2 groups were no longer significant. The period of ovarian suppression was accompanied by an equivalent period in which no $\mathrm{CL}$ were observed. In both treatment and control groups, the reappearance of a CL was preceded by a notable increase in follicular activity and indicated return to cyclic activity.

Uterine changes mirrored the changes in ovarian activity. The vaccinated mares had little ultrasonographically detectable uterine edema from the time when ovarian activity ceased until follicular activity recommenced. In control mares, uterine scores of 2 and 3 were always observed at regular 2 to 4 week intervals, except during the winter months.

\subsection{Plasma progesterone and estradiol-17 $\beta$ concentrations}

Fig. 2a shows the mean concentrations of plasma progesterone in treated and control mares from 3 weeks before to 60 weeks after first vaccination. Before treatment, the mean progesterone values in mares of both groups fluctuated between 1.7 and 11.7 $\mathrm{ng} / \mathrm{mL}$. After initial vaccination, the mean plasma progesterone concentration in the treated group fell below $1 \mathrm{ng} / \mathrm{mL}$ in week 4 and remained at this level until week 28 . From week 28 small episodic increases in mean progesterone concentration were observed, which became more pronounced towards the end of period 1. In control 
mares, mean plasma concentration of progesterone rose to $15.4 \mathrm{ng} / \mathrm{mL}$ during the breeding season and declined during winter months (weeks 32 to 46), remaining below $2.5 \mathrm{ng} / \mathrm{mL}$ from week 37 to 44 (January and February). Values rose again to $17 \mathrm{ng} / \mathrm{mL}$ as the study progressed into the new breeding season. Significant differences $(P<0.05)$ between groups were present continuously during weeks 4 to 30 and at single weeks during the following breeding season.

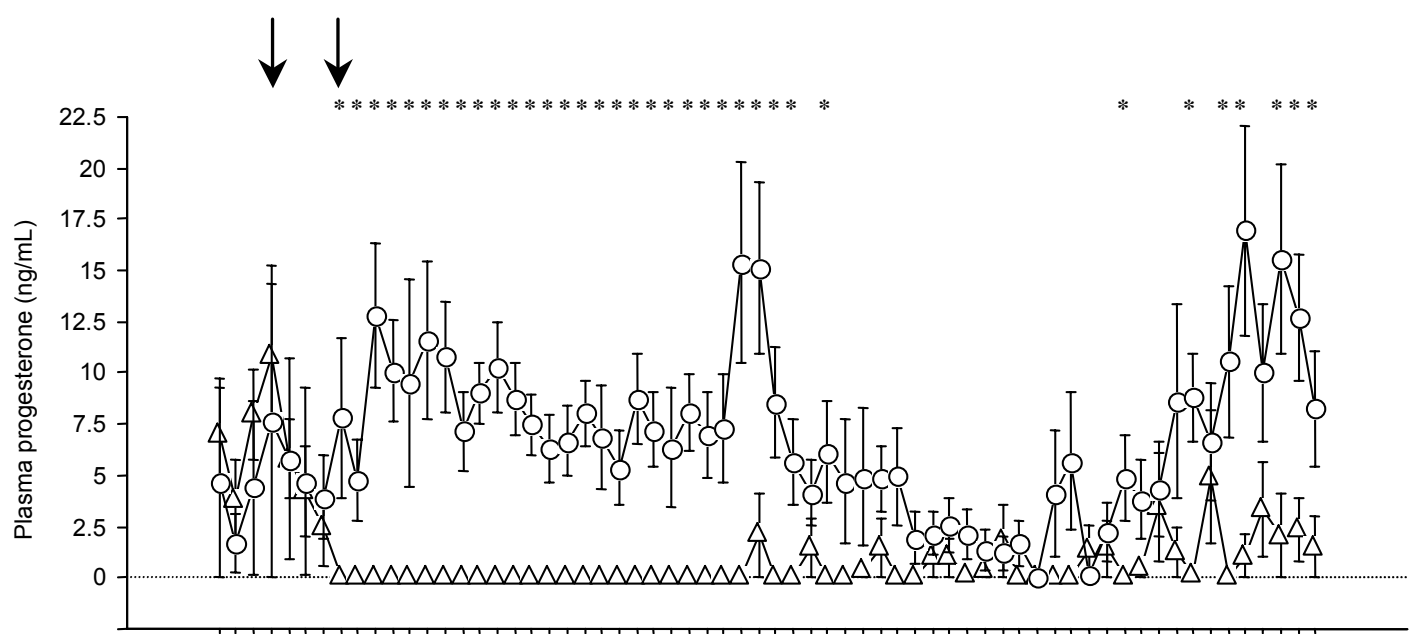

(a)

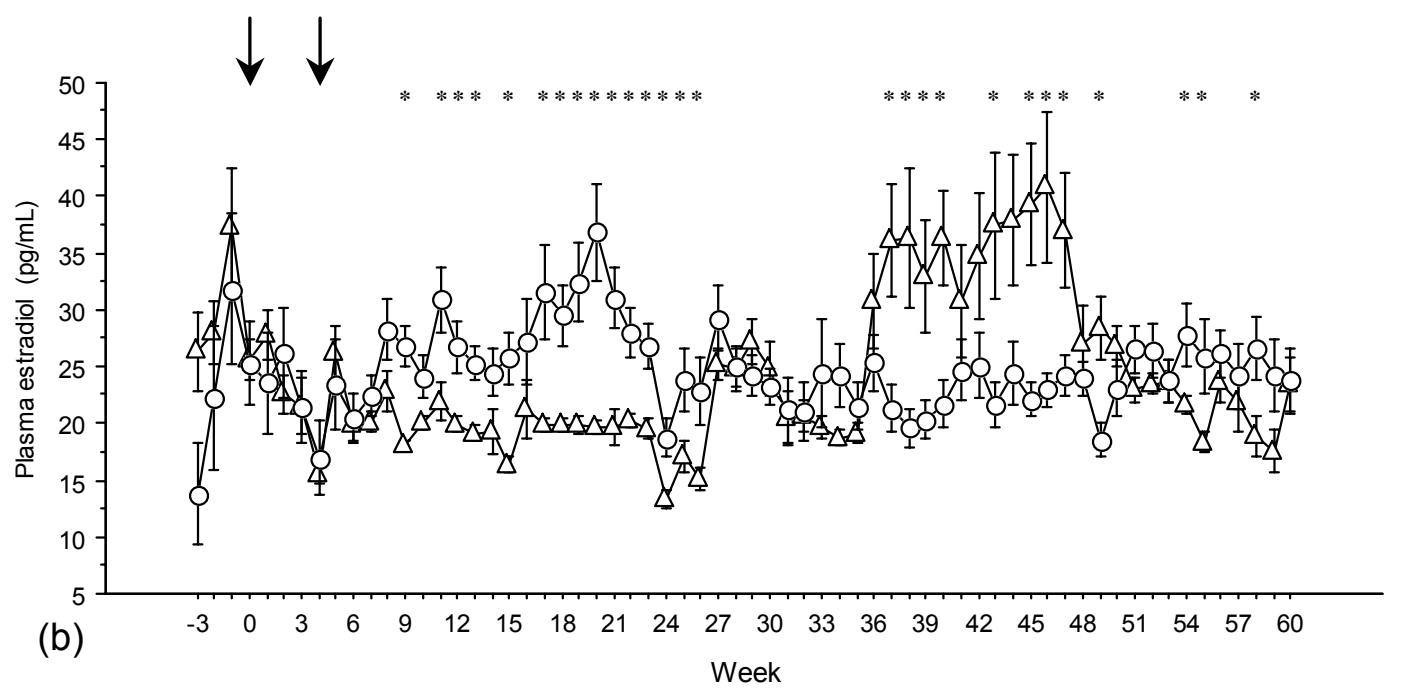

Fig. 2. Mean ( \pm S.E.M.) plasma progesterone (a) and estradiol-17 $\beta$ (b) concentrations in vaccinated $(\triangle)$ and control $(\bigcirc)$ mares before and after immunization $(\downarrow)$. Asterisks indicate a significant difference $(P<0.05$, unpaired $t$-test) between groups. 
Changes in mean concentrations of plasma estradiol-17 $\beta$ during period 1 are shown in Fig. 2b. Before treatment, mares of both groups had mean plasma estradiol-17 $\beta$ values fluctuating between 13.8 and $37.3 \mathrm{pg} / \mathrm{mL}$. After the first vaccination the mean estradiol$17 \beta$ concentrations in treated mares declined and fluctuated between 13.4 and 27.8 $\mathrm{pg} / \mathrm{mL}$ until week 35 . From week 36 to 47 (January to March) a clear increase in mean plasma estradiol-17 $\beta$ concentrations occurred in treated mares with values up to 40.9 $\mathrm{pg} / \mathrm{mL}$. Thereafter estradiol-17 $\beta$ concentrations rapidly decreased to levels observed before week 36 . In control mares mean plasma estradiol-17 $\beta$ concentrations varied between 17.0 and $36.9 \mathrm{pg} / \mathrm{mL}$ during weeks 1 to 60 . Significant differences $(P<0.05)$ between groups were mainly observed between week 9 to 26 and 36 to 50 .

\subsection{Duration of ovarian suppression and effect on estrous behavior}

All 9 immunized mares ceased cycling within 8 weeks of the first vaccination and the minimum period of ovarian suppression was 23 weeks. During period 1, three mares resumed both follicular (weeks $27,46,53$ ) and ovulatory activity (weeks 28, 51, 54). In period 2, another two mares resumed both follicular (weeks 80, 96) and ovulatory activity (weeks 84,100 ). Of the 4 treated mares that did not resume ovulatory activity during the study, 3 resumed follicular activity at weeks 48, 64 and 100. Of these, one showed regular development of large follicles for over 50 weeks without a progesterone rise, and one was destroyed for reasons unrelated to the study shortly after resumption of large follicle development. One mare remained completely suppressed for the entire duration of the study.

Six of 9 control mares became acyclic during weeks 33 and 41 (December to January) and cyclic activity was reestablished between weeks 45 and 56 (March to May). The other three control mares never fulfilled the criteria of acyclicity. Fig. 3 shows the plasma progesterone concentration together with the diameter of the largest follicle of 4 individual mares during period 1. Mare A from the control group shows an acyclic period between weeks 31 and 47. Mares B, C and D treated with Improvac ${ }^{\circledR}$ illustrate different types of reaction to the vaccine. Mare B showed the shortest period of suppression, followed by cyclic activity throughout the winter period, mare $\mathrm{C}$ showed a gradual return to follicular activity before achieving ovulation and mare $D$ remained suppressed throughout period 1 . 

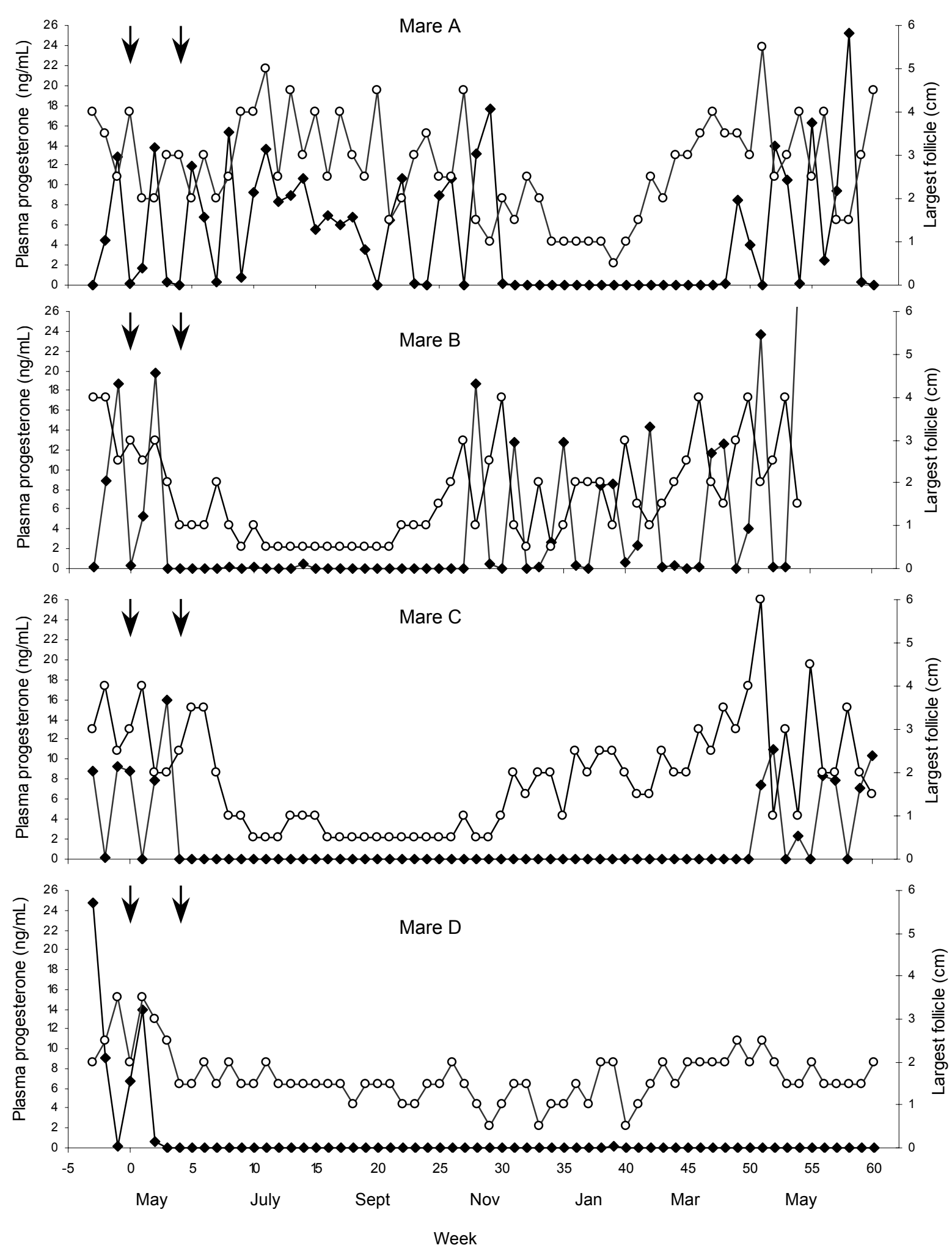

Fig. 3. Individual plasma progesterone concentration $(\diamond)$ and diameter of largest follicle $(\bigcirc)$ of a control mare $(A)$ and 3 vaccinated mares $(B, C, D)$ before and after immunization $(\downarrow)$ during period 1. 
In 4 vaccinated mares, estrous signs were absent during ovarian suppression and the first occurrence of large follicles was accompanied by estrous behavior. The other 5 mares expressed estrous signs that were not obviously related to follicle growth. Three of these mares showed sporadic estrous behavior, one was in estrus for several weeks before resuming follicular activity, while the last mare displayed estrus continuously from week 5 after vaccination until plasma progesterone concentration increased (week 84). All control mares demonstrated regular periods of estrous behavior throughout the study, except during seasonal anestrus.

\subsection{Antibody titers}

Antibody titers (Fig. 4) began to rise immediately after the first vaccination in all 9 mares and reached peak values 2 to 3 weeks after the booster injection. Maximum titers showed large individual variations and ranged between 35 and 70\% binding (1:40 dilution). Thereafter, they slowly decreased to values between 15 to $40 \%$ binding at week 100 after the first vaccination. Values at resumption of ovulatory activity ranged from 24 to $35 \%$ binding.

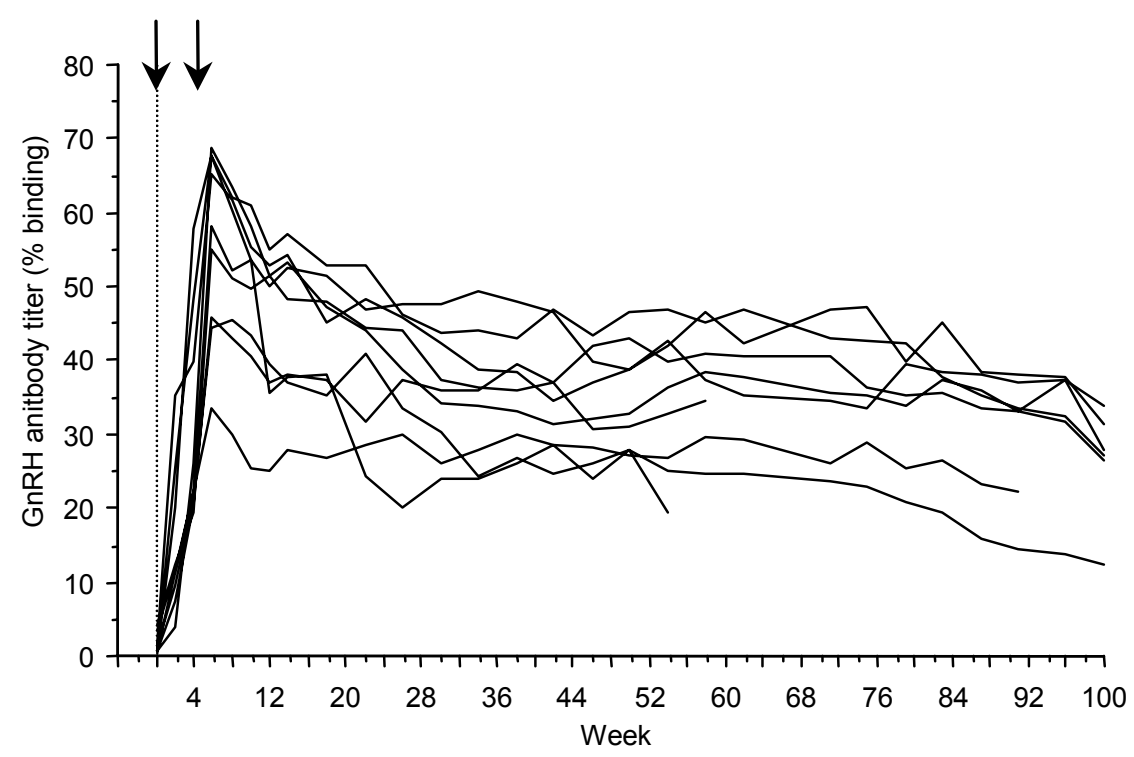

Fig. 4. GnRH antibody titers in 9 mares after $\mathrm{GnRH}$ immunization $(\downarrow)$ at weeks 0 and 4 (\% binding at a 1:40 plasma dilution). 


\subsection{Adverse effects}

Eight of 9 mares, which received $2 \mathrm{ml}$ of $\operatorname{Improvac}^{\circledR}$, showed reactions of varying severity, including swelling and pain at the injection site, stiffness of the neck, pyrexia and apathy (Table 2). The degree and duration of reactions varied individually and were more serious after the booster injection. A mean increase in body temperature was only evident on the day after each vaccination (mean 38.8 and $38.7^{\circ} \mathrm{C}$ ). However, individual peaks up to $39.8^{\circ} \mathrm{C}$ were recorded. Swelling and pain was most evident on the second day after vaccination. All reactions had subsided by 4 and 5 days after primary and booster vaccination, respectively.

\section{Table 2}

Incidence of adverse effects of immunizing mares against GnRH using Improvac $^{\circledR}$

\begin{tabular}{lcc}
\hline Effect & \multicolumn{2}{c}{ Number of mares } \\
& Primary immunization & Booster immunization \\
\hline Number of mares immunized & 9 & 9 \\
Pyrexia & $8(88.9 \%)$ & $7(77.8 \%)$ \\
Pain at site of injection & $4(44.4 \%)$ & $7(77.8 \%)$ \\
Swelling at site of injection & $3(33.3 \%)$ & $6(66.7 \%)$ \\
Stiffness of the neck & 0 & $7(77.7 \%)$ \\
Apathy & 0 & $2(22.2 \%)$ \\
\hline
\end{tabular}




\section{Discussion}

The results of this study demonstrate that administration of the $\mathrm{GnRH}$ vaccine Improvac ${ }^{\circledR}$ to mares elicits clear inhibitory changes in endocrine, ovarian, uterine and behavioral parameters.

The effect of immunization against $\mathrm{GnRH}$ on ovarian activity was dramatic and rapid, and allowed clear differentiation between treated and control mares. Follicular development decreased such that by 4 weeks after the first vaccination, the number of medium and large follicles differed significantly between the treatment and control group. The variation in the amount of time (2-7 weeks) from vaccination to cessation of ovarian activity was probably due to immunization at different stages of the cycle. In mares with large follicles (estrus), cessation time was longer than in mares vaccinated during the luteal phase (diestrus). A similar study [27] carried out with a smaller number of mares also showed a rapid response to vaccination with follicular atresia and significant reduction in ovarian length 3 to 4 weeks after the first injection. In our study the ovarian response was always bilateral and the marked decrease in number and size of follicles resulted in ovaries that were significantly smaller than those in the control mares for 30 consecutive weeks. Resumption of ovulatory activity was achieved in 5 of 9 mares and varied between 27 and 100 weeks after the first vaccination. In these mares the period of time that elapsed between the first signs of follicular activity and the appearance of a progesterone-secreting CL was 1-5 weeks. These results demonstrate that resumption of follicular and ovulatory activity after immunization against $\mathrm{GnRH}$ is highly variable in spite of all mares being immunized at the same time with the same dose of the vaccine and despite showing a similar decline of anti-GnRH titers. A highly individual duration of ovarian suppression in vaccinated mares was also reported by Dalin et al. [28], where one mare showed a large time lapse between resumption of follicular activity and first ovulation and another was completely suppressed for approximately 14 months. The suppression of ovarian activity is brought about by the binding of endogenous $\mathrm{GnRH}$ to circulating antibodies, preventing $\mathrm{GnRH}$ from binding to receptors in the anterior pituitary. Studies on mares have shown that secretion (and possibly production) of $\mathrm{LH}$ is highly dependent on $\mathrm{GnRH}$, while $\mathrm{FSH}$ secretion is at least partially independent of $\mathrm{GnRH}$ stimulation [25,26]. Therefore, the growth of small antral follicles that we observed in all vaccinated mares and that has been previously 
described in mares [26,28], heifers [17] and ewes [31], may be relatively independent of $\mathrm{GnRH}$ availability. Because of the more comprehensive suppression of LH then of FSH achieved by vaccination against $\mathrm{GnRH}$ [25], further development, maturation and ovulation may be prevented.

Resumption of follicular and ovulatory activity in vaccinated mares may be comparable to the transitional period seen in mares between seasonal anestrus and the breeding season [32] where large $(\geq 3 \mathrm{~cm})$ anovulatory follicles grow and regress before an ovulatory follicle develops with sufficient estradiol production to increase LH secretion and induce ovulation.

A significant finding of the current study was that 3 mares showed no signs of luteal activity despite regular development of large follicles and that one mare showed neither luteal activity nor follicle development for 2 years after vaccination. Without having conducted further tests we are unable to say whether immunization resulted in reduced sensitivity of the pituitary gland to $\mathrm{GnRH}$ or decreased pituitary production and / or secretion of $\mathrm{LH}$ and $\mathrm{FSH}$. Furthermore, we cannot entirely exclude the possibility of some degree of permanent impairment of hypothalamic or pituitary function, as observed after the immunization of ewes against GnRH early in life [31].

Levels of plasma progesterone and estradiol-17 $\beta$ concentration also showed marked differences between the treatment and control groups. Plasma progesterone concentration is considered the best indicator for the resumption of estrous cycles in mares [27,28]. Cyclic activity in control mares was demonstrated by regular progesterone increases, which correlated with recent ovulations. In all vaccinated mares the indirect effect of $\mathrm{GnRH}$ inactivation on $\mathrm{LH}$ secretion was best evidenced by the low progesterone concentrations $(<1 \mathrm{ng} / \mathrm{ml})$, indicating the absence of ovulations, during at least 5 months. The effect of vaccination on estradiol-17 $\beta$ concentrations was less dramatic. In control mares, levels fluctuated throughout the whole study and higher concentrations were observed when the number of large follicles was increased. In vaccinated mares, plasma estradiol- $17 \beta$ concentrations generally fluctuated at a lower level than in control mares until the end of the breeding season. From January to March mean estradiol-17 $\beta$ concentrations in vaccinated mares were significantly higher than in control mares due to abnormally elevated levels seen in 3 mares. As the number and size of the follicles during this time was not higher than at any other time during period 
1 , it is speculated that the origin of the estradiol- $17 \beta$ may be increased production by granulosa cells of small and antral follicles. It is also possible that the estradiol was of adrenal origin since sexual steroids are also produced by the adrenal cortex in response to ACTH [5].

The manifestation of estrous behavior in anovulatory mares as seen in this study is a phenomenon that has been described after vaccination against GnRH [28], after treatment with a GnRH agonist [14] and following ovariectomy [5]. In the absence of significant progesterone concentrations, only small amounts of estradiol are needed for induction of estrous signs. That estrous behavior in ovariectomized mares was successfully suppressed by dexamethasone treatment [5] further underlines the possible involvement of sexual steroids originating from the adrenal cortex.

All mares showed an immediate and distinct antibody response after the first vaccination with peak levels obtained 2 to 3 weeks after the booster injection. The titer decline was similar in all mares, with a rapid fall during the first few weeks followed by a steady decline until 100 weeks after the first vaccination. Antibody titers were not clearly related to the duration or the degree of ovarian suppression and titers at reversal varied considerably. Other studies in mares [26,28], heifers [17] and ewes [33] also report a large variation in antibody response, duration of suppression of reproductive activity and antibody titer at reversal. It may be concluded that thresholds at which antibody titers retain effectiveness are variable between individuals, and may well be related to genetic factors and the individuals' specific immune response [33].

The adverse effects to vaccination with Improvac $^{\circledR}$ were quite severe, similar to those described by Dalin et al. in mares [28] and Dowsett at al. in stallions [23] using different vaccine formulations. Improvac ${ }^{\circledR}$, originally developed to control boar taint in pigs has been shown to be well tolerated in pigs $[34,35]$. The high incidence of adverse effects using Improvac ${ }^{\circledR}$ in horses may either be caused by the adjuvant or the carrier protein present in the vaccine. A new vaccine (Equity ${ }^{\mathrm{TM}}$, Pfizer Animal Health, Australia), with a modified adjuvant and carrier protein has been designed specifically for use in the horse and is well tolerated (authors: unpublished observations).

In conclusion, this study demonstrates that reproductive cyclicity in adult mares can be reliably suppressed by active immunization against $\mathrm{GnRH}$. However, the duration of the inhibitory effect is highly variable, not clearly related to $\mathrm{GnRH}$ antibody titers and 
resumption of ovulatory activity may require more than 100 weeks. Moreover, ovarian suppression does not always prevent the occurrence of sexual behavior. Because of the failure of some mares in this study to return to reproductive cyclicity, it would be of practical significance to determine the long-term effects of repeated vaccination on the fertility of mares.

\section{Acknowledgements}

We would like to thank J.-F. Johner, Chalet a Gobet, for providing the mares and G. Cosentino of the Laboratory Dr. Risch, Liebefeld, for the hormone analyses. 


\section{References}

[1] Roberts SJ, Beaver BV. The use of progestagen for aggressive and hypersexual horses. In: Robinson NE, editor. Current therapy in equine medicine. London: Saunders;1987.p.129-31.

[2] Skelton KV, Dowsett KF, McMeniman NP. Ovarian activity in fillies treated with anabolic-steroids prior to the onset of puberty. J Reprod Fertil Suppl 1991;44:35156.

[3] Lefranc AC, Allen WR. Nonpharmacological suppression of estrus in the mare. Equine Vet J 2004;36:183-5.

[4] Ginther OJ. Sexual behavior. In: Reproductive biology of the mare, basic and applied aspects. Wisconsin: Equiservices;1979.p.59-82.

[5] Asa CS, Goldfoot DA, Garcia MC, Ginther OJ. Sexual behavior in ovariectomized and seasonally anovulatory pony mares (Equus caballus). Horm Behav 1980;14:46-54.

[6] Hooper RN, Taylor TS, Varner DD, Blanchard TL. Effects of bilateral ovariectomy via colpotomy in mares: 23 cases (1984-1990). J Am Vet Med Assoc 1993;203:1043-46.

[7] Stout TA, Colenbrander B. Suppressing reproductive activity in horses using $\mathrm{GnRH}$ vaccines, antagonists or agonists. Anim Reprod Sci 2004;82-83:633-43.

[8] Guillaume DB, Bruneau B, Briant C. Comparison of the effects of two GnRH antagonists on $\mathrm{LH}$ and $\mathrm{FSH}$ secretion, follicular growth and ovulation in the mare. Reprod Nutr Dev 2002;42:251-64.

[9] Watson ED, Pedersen HG, Thomson SR, Fraser HM. Control of follicular development and luteal function in the mare: effects of a $\mathrm{GnRH}$ antagonist. Theriogenology 2000;54: 599-609.

[10] Bertschinger HJ, Trigg TE, Jöchle W, Human A. Induction of contraception in some African wild carnivores by downregulation of $\mathrm{LH}$ and $\mathrm{FSH}$ secretion using the GnRH analogue deslorelin. Reproduction Suppl 2002:60:41-52. 
[11] Johnson CA, Thompson DL, Cartmill JA. Pituitary responsiveness to $\mathrm{GnRH}$ in mares following deslorelin acetate implantation to hasten ovulation. J Anim Sci 2002;80:2681-7.

[12] Montovan SM, Daels PF, Rivier J, Hughes JP, Stabenfeldt GH, Lasley BL. The effect of a potent $\mathrm{GnRH}$ agonist on gonadal and sexual activity in the horse. Theriogenology 1990:33;1305-21.

[13] Mumford EL, Squires EL, Jochle E, Harrison LA, Nett TM, Trigg TE. Use of deslorelin short-term implants to induce ovulation in cycling mares during 3 consecutive estrous cycles. Anim Reprod Sci 1995;39:129-40.

[14] Fitzgerald BP, Peterson KD, Silvia PJ. Effect of constant administration of a gonadotropin-releasing hormone agonist on reproductive activity in mares preliminary evidence on suppression of ovulation during the breeding-season. Am J Vet Res 1993;54:1746-51.

[15] Esbenshade KL, Britt JH. Active Immunization of gilts against gonadotropinreleasing hormone - effects on secretion of gonadotropins, reproductive function, and responses to agonists of gonadotropin-releasing hormone. Biol Reprod 1985;33:569-77.

[16] Wettemann RP, Castree JW. Immunization of heifers against gonadotropinreleasing hormone delays puberty and causes the cessation of estrous cycles. Anim Reprod Sci 1994:36: 49-59.

[17] Prendiville DJ, Enright WJ, Crowe MA, Finnerty M, Hynes N, Roche JF. Immunization of heifers against gonadotropin-releasing hormone: antibody titers, ovarian function, body growth, and carcass characteristics. J Anim Sci 1995;73:2382-9.

[18] Thompson DL. Immunization against $\mathrm{GnRH}$ in male species (comparative aspects). Anim Reprod Sci 2000;60-61:459-69.

[19] D'Occhio MJ. Immunological suppression of reproductive functions in male and female mammals. Anim Reprod Sci 1993;33:345-72.

[20] Fayer-Hosken RA, Grobler D, Van Altena JJ, Bertschinger HJ, Kirkpartrik JF. Immunocontraception of African elephants. Nature 2001;411:766. 
[21] Simms MS, Scholfield DP, Jacobs E, Michaeli D, Broome P, Humphreys JE et al. Anti-GnRH antibodies can induce castrate levels of testosterone in patients with advanced prostate cancer. Br J Cancer 2000;83:443-6.

[22] Schanbacher BD, Pratt BR. Response of a cryptorchid stallion to vaccination against luteinising hormone releasing hormone. Vet Rec 1985;116:74-5.

[23] Dowsett KF, Knott LM, Tshewang U, Jackson AE, Bodero DA, Trigg TE. Suppression of testicular function using two dose rates of a reversible water soluble gonadotropin-releasing hormone $(\mathrm{GnRH})$ vaccine in colts. Aust Vet $J$ 1996;74:228-35.

[24] Malmgren L, Andresen O, Dalin AM. Effect of GnRH immunization on hormonal levels, sexual behavior, semen quality and testicular morphology in mature stallions. Equine Vet J 2001;33:75-83.

[25] Garza FJr, Thompson DLJr, French DD, Wiest JJ, St George RL, Ashley KB et al. Active immunization of intact mares against gonadotropin-releasing hormone: differential effects on secretion of luteinizing hormone and follicle-stimulating hormone. Biol Reprod 1986;35:347-52.

[26] Safir JM, Loy RG, Fitzgerald BP. Inhibition of ovulation in the mare by active immunization against LHRH. J Reprod Fertil Suppl 1987;35:229-37.

[27] Tshewang U, Dowsett KF, Knott LM, Trigg TE. Preliminary study of ovarian activity in fillies treated with a GnRH vaccine. Aust Vet J 1997;75:663-7.

[28] Dalin AM, Andresen O, Malmgren L. Immunization against $\mathrm{GnRH}$ in mature mares: antibody titres, ovarian function, hormonal levels and estrous behavior. $\mathrm{J}$ Vet Med 2002;49:125-31.

[29] Ginther OJ. The Uterus. In: Ultrasonic imaging and reproductive events in the mare. Wisconsin: Equiservices;1986.p.173-94.

[30] Finnerty M, Enright WJ, Morrison CA, Roche JF. Immunization of bull calves with a $\mathrm{GnRH}$ analogue-human serum albumin conjugate: effect of conjugate dose, type of adjuvant and booster interval on immune, endocrine, testicular and growth responses. J Reprod Fertil 1994;101:333-43. 
[31] Brown BW, Mattner PE, Carroll PA, Hoskinson RM, Rigby RD. Immunization of sheep against $\mathrm{GnRH}$ early in life: effects on reproductive function and hormones in ewes. J Reprod Fertil 1995;103:131-5.

[32] Donadeu FX, Ginther OJ. Follicular waves and circulating concentrations of gonadotrophins, inhibin and oestradiol during the anovulatory season in mares. Reproduction 2002;124:875-85.

[33] Keeling BJ, Crighton DB. Reversibility of the effects of active immunization against LH-RH. In: Crighton DB, editor. Immunological aspects of Reproduction in Mammals. London: Butterworths; 1984.p.379-397

[34] Dunshea FR, Colantoni C, Howard K, McCauley I, Jackson P, Long KA et al. Vaccination of boars with a $\mathrm{GnRH}$ vaccine (Improvac) eliminates boar taint and increases growth performance. J Anim Sci 2001;79:2524-35.

[35] Jaros P, Bürgi E, Stärk KDC, Claus R, Hennessy D, Thun R. Effect of active immunization against $\mathrm{GnRH}$ on androstenone concentration, growth performance and carcass quality in intact male pigs. Livest Prod Sci 2005;92:31-8. 


\section{Lebenslauf}

\begin{tabular}{ll} 
Name & \multicolumn{1}{l}{ Isabel Imboden } \\
Geburtsdatum & 9.10 .1977 \\
Geburtsort & Wellington NZ \\
Nationalität & Schweiz, Großbritannien, Neuseeland \\
Heimatort & Unterseen BE und St Gallen \\
1984 - 1990 & Kings College Primary School, Cambridge, GB \\
$1990-1993$ & $\begin{array}{l}\text { General Certificate of Secondary Education (GCSE) } \\
\text { St Mary's School, Cambridge, GB } \\
1996-2001\end{array}$ \\
A - Levels (Britische Matura) \\
Hills Road Sixth Form College, Cambridge, GB \\
Studium in Equine Science, University of Bristol, GB \\
Studium der Veterinärmedizin an den Universitäten Basel \\
und Bern
\end{tabular}

2001

Abschlussprüfung an der Veterinärmedizinischen Fakultät der Universität Bern

$2002-2003$

Tierärztin am Nationalgestüt in Avenches

$2003-2006$

Assistentin am Sportmedizinischen Leistungszentrum der Pferdeklinik der Vetsuisse Fakultät, Universität Zürich

Seit 2005

Assistentin, Pferdepraxis Dr. M. Schmid, Frauenfeld 